\title{
DÓNDE ESTÁS CONSTANZA (1980) DE JOSÉ LUIS ROSASCO: ALEGORÍAS REFUNDACIONALES DE LA NACIÓN ${ }^{1}$ \\ Dónde estás Constanza (1980) by José Luis Rosasco: Re-Foundational Allegories of the Nation
}

Mario Lillo C.*

Resumen

En este artículo se lleva a cabo una relectura de la novela Dónde estás Constanza, de José Luis Rosasco a partir de algunas estrategias discursivas y de una poética de la historia que revelan que este texto, cuya recepción lo catalogó en el género de la novelita rosa adolescente, también puede ser leído como una alegoría del poder y del Super yo enmascarado.

Palabras clave: Narratología, alegoría, ideología, poder, novela rosa adolescente.

Abstract

The article carries out a re-reading of the novel Dónde estás Constanza, by José Luis Rosasco, out of some discursive strategies and a poetic of history that reveals that this text, whose reception catalogued it in the genre of the teen pink Novella, can also be read as an allegory of the power and the masked super-ego.

Key words: Narratology, allegory, ideology, power, teen pink Novella.

Dónde estás Constanza (1980) de José Luis Rosasco es una novela que llama la atención por su aparente distancia con las temáticas esperables en relatos cuyo contexto de producción se enmarca en pleno período de la dictadura. Por lo mismo, nos interesa examinar aspectos narratológicos del texto que nos permitan detectar su manera de impugnar o de reforzar el sistema de valores ideológicos vigente en la superestructura de una sociedad bajo dictadura, mediante estrategias textuales de revelación, ocultamiento o transformación del mundo referencial, examen que posteriormente centraremos en la composición alegórica que, desde nuestra perspectiva, desarrolla José Luis Rosasco para remitir el sentido patente de la diégesis a "otro" sentido. Previamente, y siguiendo a Nietzsche, examinaremos muy brevemente la concepción de la historia implícita en el texto, las estrategias discursivas que emplea el autor para entregar su visión de mundo, en especial su modo de tramar la historia, la argumentación formal empleada y, por supuesto, la implicación ideológica subyacente a esta historia de amor preadolescente.

\footnotetext{
${ }^{1}$ Este trabajo forma parte del Proyecto: "La novela de la dictadura en Chile" de la Facultad de Letras de la Pontificia Universidad Católica de Chile.
} 


\section{ANÁLISIS NARRATOLÓGICO. FUNCIONES NARRATIVAS EN LA NOVELA}

Los núcleos o motivos básicos (cardinales) de la historia son: la llegada de los Glicker a la casa; la fiesta ofrecida por esta familia a vecinos y parientes; la cena de Constanza y Alex en el restaurante La Chateleine; la huida posterior de ambos al refugio en la precordillera de la ciudad; el retorno al hogar de Álex. En cuanto a algunos motivos complementarios, catálisis o indicios, podemos citar el relato del capitán Larsen que hace Jaime a su amigo Alex acerca del instinto de inmortalidad o supervivencia; la historia de amor perdido del tío César; el estado material del refugio; el vaticinio de la Rucia, hermana mayor de Constanza acerca del cambio de casa.

\section{PERSPECTIVA DEL NARRADOR O PUNTO DE VISTA}

La narración evidencia una perspectiva interpretativa de carácter monológico, pues predomina el punto de vista del narrador reproducido por los personajes de la abuela, la mamá y el tío César. El narrador con omnisciencia selectiva y los adultos Corsiglia enuncian aquella ideología del sentido común, de la conducta comme il faut presente además en los intertextos (mise en abyme) de Jack London y en el relato del tío César. Por lo tanto, no hay dialogismo o polifonía en el sentido bakhtiniano. El texto presenta ciertas palabras y formas que relacionan la novela indirectamente con el contexto de producción. Así por ejemplo, cuando en la conciencia de Alex se reproduce solidariamente la ideología oficial, que no da lugar a las aventuras ni fantasías, imperante en la época de la escritura a finales de los años 70: “¿Cómo es que Constanza no se había dado cuenta? ¿Quién se creía que era? ¿Tom Sawyer y Huckleberry Finn?” (107). Esta ideología es reforzada por la madre cuando Álex vuelve a casa después de su aventura: "Estás seguro de que se te pasó totalmente la fiebre? [...] nada de recaídas entonces" (108), y por el desenlace de la historia de amor fracasado del tío César. Estos elementos dejan como enseñanza que aventuras o deslices son sancionados sin apelación, como le sucedió al tío César con la joven Ilse.

La perspectiva moral, es decir, la actitud del narrador frente al protagonista, es de simpatía, de adhesión con el devenir y el destino de Alex, pues su función narrativa es servir de paradigma del futuro ciudadano ejemplar susceptible de cometer errores, pero capaz de reconocerlos y enmendarlos gracias al reconocimiento y la aceptación de la recta doctrina emanada de los valores familiares del orden, la obediencia y la disciplina.

ESPACIALIDAD DEL RELATO

Los espacios configurados en el mundo del relato son el barrio, las casas de los Corsiglia y Sandoval-Glicker - cuya función narrativa es señalar los polos opuestos- el cine de barrio, el restaurante, el refugio. Las calles no son sino un mero espacio de tránsito que comunica los espacios cerrados. Muy 
relevante es la configuración de ciertos espacios como estados de ánimo. Así por ejemplo, el refugio en la precordillera reproduce el estado de ánimo del protagonista y anticipa el desenlace "virtuoso" de la aventura. Además, el texto insinúa una suerte de espacio del mito urbano secularizado, representado por el cine Rialto como lugar donde se forjan los mitos personales de la iniciación al amor y el mito colectivo del mundo de los actores y actrices.

\section{TEMPORALIDAD DEL RELATO}

La manera como el hombre se relaciona con la historia es materia sobre la cual reflexionó Friedrich Nietzsche en el texto "De la utilidad y de los inconvenientes de los estudios históricos para la vida", incluido en su conocida obra Consideraciones intempestivas (1967). El filósofo distingue tres maneras de entender la historia: monumental, anticuaria y crítica. Para Nietzsche

[C]uando un hombre que desea realizar algo grande tiene necesidad del pasado, se apropia de él mediante la historia monumental; a su vez, el que persiste en lo habitual y venerado a lo largo del tiempo, cultiva el pasado como historiador anticuario; y sólo aquel a quien una necesidad presente oprime el pecho y que, a toda costa, quiere librarse de esa carga, siente la necesidad de la historia crítica, es decir, de la historia que juzga y condena (en líneawww.elabedul.net/Documentos/De_la_utilidad.doc).

El hecho de que la historia de Rosasco se circunscriba a momentos cardinales en la vida del protagonista permite sostener que ella se inscribe dentro del concepto de historia monumental nietzscheana. Se trata entonces de una narración sintética en la cual los hechos se seleccionan y condensan. El narrador no es contemporáneo a los hechos, sino que narra desde una cierta distancia nostálgica. El relato primario se sitúa en un presente de fines de los 70 y rememora una historia muy acotada en el tiempo y el espacio acontecida 25 años antes, pues en el texto se menciona, por ejemplo, la música de moda de Elvis Presley o al actor Fernando Lamas, el latin lover de moda.

A pesar de su carácter de narración sintética existe cierta coincidencia entre el tiempo vivido y el tiempo narrado, pues prácticamente no se detectan anacronías, no hay analepsis, pero sí una especie de circularidad producida por el empleo del pretérito imperfecto cuando se habla de la vida del barrio o del cine Rialto. Esta circularidad es característica de la narración rememorante.

El tiempo de la escritura es 1980, y el de la aventura corresponde a la década del $50 \mathrm{y}$ abarca aproximadamente dos a tres meses condensados en pocas secuencias: la llegada de los Glicker, la fiesta, el relato de la historia de amor del tío César (cap., VIII), la cena en La Chateleine, la huida de los dos prepúberes y el retorno de Álex a su casa. Ahora bien, el tiempo narrado -años 50corresponde a una época histórica previa al estallido de los grandes conflictos sociales, políticos y culturales en Occidente enmarcados en la Guerra Fría, y que 
habrían de tener gran influencia en el contexto nacional, tales como la Revolución Cubana, la Reforma Agraria en Chile impuesta por la Alianza para el Progreso, la construcción del Muro de Berlín, la agudización de la Guerra de Viet Nam, la invasión norteamericana a Santo Domingo, la invasión soviética a Checoslovaquia, la revolución de las flores, la guerrilla del Che Guevara en Bolivia y de Camilo Torres en Colombia, el mayo del ' 68 de París, la matanza de Tlatelolco en el mismo año, la guerrilla urbana o rural en Uruguay y Argentina, etc. De algún modo, estos conflictos potenciaron, abonaron o sirvieron de caja de resonancia para las luchas sociales, los experimentos, las reformas o las rupturas que intentaron cambiar por diversas vías la situación de pobreza, desigualdad, injusticia y explotación a que parecía sentenciado el subcontinente latinoamericano, situación que se manifestó en algunas de las grandes novelas del Boom. Pero ya antes del estallido del conflicto algunos intelectuales y economistas sostenían, en Chile, que era posible un futuro distinto al presente diagnosticado por Jorge Ahumada (2000). El "desarrollo hacia adentro" recetado por CEPAL permitiría eventualmente redimir de una condena según la cual nuestro país era y seguiría siendo "un caso de desarrollo frustrado", como lo expresara en el texto homónimo el economista Aníbal Pinto (1962); un Chile que - aún a comienzos de este siglo XXI- el historiador Alfredo JocelynHolt (2000:23) describe como de potencialidades desperdiciadas, de decadencia sistemática, de crisis larvadas, de consensos socavados, de debilitamiento moral, en fin, de descomposición nacional. Pero estos conflictos ya estaban latentes en aquella época de los 50 y se expresaban tan sólo como escarceos intermitentes y sin mayor eco en una opinión pública mucho menos informada que hoy. En nuestra lectura de la novela de Rosasco, el tiempo vivido diegéticamente es previo al de la pérdida de la inocencia en la dinámica política y en la sociabilidad, como por ejemplo queda establecido en la caracterización alegórica del barrio y de sus habitantes, hasta el momento de la irrupción de los Sandoval-Glicker. El Chile de la familia Corsiglia es anterior a la sucesión de pseudo o protorevoluciones que marcaron la vida nacional en una etapa de no más de 25 años saturada de acontecimientos históricos que aún estamos intentando procesar: la "Revolución en libertad" freísta; la "Revolución con empanadas y vino tinto" allendista; y la silenciosa (Joaquín Lavín dixit) "Revolución neoliberal" pinochetista, posteriormente sometida a una serie de make ups, pero aún vigente. En el Chile provinciano de entonces, gobernado por un militar y ex dictador - como diría Borges mutatis mutandis - abrumado y casi anulado por la democracia, los 50 son una década que observa desde la obligada distancia geográfica y con desacomodo cultural la incipiente rebeldía de la nueva generación expresada en contorsiones pélvicas, un verdadero frenesí kinésico provocado por el rupturista Rock and Roll. Es una década en la cual muchos países latinoamericanos continuaban en su siesta colonial y, como sostuvo Heinrich Böll (1952) respecto de los nobles franceses de antes de 1789 (y de la disyuntiva del escritor alemán 
tras la hecatombe de la Segunda Guerra Mundial: denuncia o elipsis del pasado) parecían jugar a la gallinita ciega mientras se incubaban sotto voce los movimientos sociales, políticos y culturales de ruptura que harían inviable situar un relato como el de Rosasco antes o después de los 50 ¿Por qué situar la historia en esta década aparentemente tan desperfilada? Justamente por eso, porque una narración que refuerza los valores conservadores involucrados en el relato es difícil de escenificar verosímilmente en una década como la de los 60 marcada mayoritariamente por el cambio y el conflicto cultural. Como sostienen Sofía Correa et al., respecto a los años 60, se trata de “...una época de trastornos en las modas, estéticas, consignas, representaciones y conductas, liderada por sujetos nuevos como los jóvenes y las mujeres en el marco de una cultura de masas que se consolidaba, todo lo cual irrumpió en la vida pública con inusitada magnitud. La década se convirtió en una verdadera bisagra histórica" (2001:226). Tampoco era plausible escenificar el relato en la década de los 70 , atravesada por conflictos políticos y militares que habrían sido un telón de fondo no funcional al proyecto edificante sugerido por la novela. Casi nada de lo anterior está en el aire en la década del 50, entre otras causas, porque muchas sociedades occidentales aún viven en el período de postguerra mundial asociado a restricciones derivadas del esfuerzo reconstructor. Este periodo fijaba prioridades que impedían el desahogo y la distensión de los conflictos sociales o culturales larvados, aun cuando en el Chile del General Ibáñez se produjo una cierta efervescencia política que, en todo caso, no involucró directamente sino a las elites del poder político, y tuvo manifestaciones aisladas de descontento popular vinculadas a problemas muy circunscritos, como un alza del valor del pasaje de la locomoción colectiva a comienzos de 1957. En las décadas del 60 y del 70, un desenlace cómico como el que se produce en la novela habría sido anacrónico, dado que la historia seguía un vector en apariencia irreversible que conducía más bien a la tragedia — como producto del inevitable enfrentamiento según la retórica en boga - que a la comedia de reconciliación de las fuerzas en pugna. Es decir, se trataría de un problema de plausibilidad histórica ligada a la verosimilitud literaria.

\section{ESTRATEGIAS DISCURSIVAS}

De acuerdo con lo planteado por Hayden White en Metahistoria (1992:1821), el modo de tramar en la novela mutatis mutandis es cómico, puesto que el relato diseña en su estructura de profundidad un esquema en el cual se produce una confrontación entre dos fuerzas, una conservadora y una rupturista. La primera está representada por la familia de Alex: madre, abuela y, en menor grado, el tío César; la segunda fuerza está encarnada en el disfuncional grupo familiar SandovalGlicker. Por un instante parece triunfar el bando disgregador del orden existente, pero el sedimento valórico, aquello que en el campo de la política Diego Portales denominó "el peso de la noche", hace sentir su influencia en la decisión de Alex de declarar la fuga-aventura como una insensatez, y finalmente prevalece el buen 
sentido y el recto orden de la familia, del barrio, de la comunidad. Por ello, la derrota de las fuerzas dis-ruptoras no imprime un signo de tragedia a la historia relatada, sino que opera como elemento aleccionador en el espíritu de edificación moral que impulsa al principal involucrado a retomar la senda del bien y del recto proceder. Como sostiene White respecto de este tipo de desenlace, propio del relato cómico "...las reconciliaciones que ocurren al final de la comedia son reconciliaciones de hombres con hombres, de hombres con su mundo y su sociedad; la condición de la sociedad es representada como más pura, más sana y más saludable como resultado del conflicto..." (1992:20). Por eso, al final del relato, y a pesar de la frustrada experiencia amorosa, Álex retorna al colegio sintiendo "...adentro una curiosa sensación bienhechora" (112). El muchacho se ha reconciliado con su núcleo social gracias a la experiencia que lo ha enriquecido y le ha señalado los límites que no conviene trasgredir, so pena de caer víctima de la "fiebre" o del "cáncer".

Por lo dicho, y siguiendo lo planteado por White (22-31), la argumentación formal de la novela de Rosasco tiende hacia el mecanicismo, puesto que, por una parte, el relato sigue un esquema en el cual a cada acto o decisión de los personajes le sigue una consecuencia inmediata que adopta un carácter aleccionador; y por otra parte, en una explicación que se puede asociar con la alegoría, White señala que para el mecanicista "...las entidades individuales son menos importantes como evidencia que las clases de fenómenos a los que puede demostrarse que pertenecen..." (27). No obstante, esas clases son para él menos importantes que las leyes puestas de manifiesto por las regularidades que evidencia un texto. Costumbres, instituciones, leyes, formas de arte son menos substanciales como evidencias que la especie, clase o tipificación genérica que ejemplifican. Así entonces, en el diagrama de la novela aquellas entidades individuales llamadas "barrio", "familia", "casa precaria", "cine", “carretón”, "caserón-refugio", "fuga”, "fiebre”, "desaparición”, “Álex”, “Constanza” o los miembros de ambas familias uno por uno, etc., tipifican, evidencian, ejemplifican, alegorizan en nuestra propuesta una situación a la vez genérica — la irrupción del caos en un mundo en orden precario, digamos La muerte en Venecia o Casa de campo- y una situación particular en la historia nacional reciente. Como ejemplo específico de la relación mecanicista causa-consecuencia en el texto se puede aludir a la fiesta familiar de los Sandoval-Glicker que favorece el encuentro de los héroes; a este encuentro le sigue la cena de ambos en La Chateleine que programa la fuga de Alex de su casa; la fuga tiene como consecuencia inmediata una epifanía inducida por la precariedad y el desorden del refugio que debía ser escenario de su vida con Constanza; la epifanía provoca a su vez la huida del refugio por parte del muchacho, y la aventura como un todo provoca un estado febril extremo del que se recupera con auxilio del tío César.

De entre las tres maneras de entender la historia según Nietzsche que mencionáramos anteriormente, el relato de Rosasco opta simultáneamente por una 
concepción monumental y una crítica de la Historia y de la petite histoire. Como sosteníamos, la novela se aproxima a la historia monumental nietzscheana por cuanto el narrador se concentra en momentos claves para el desarrollo de la historia y no pierde el tiempo en catálisis, excepción hecha de la historia del tío César, en descripciones morosas o pintoresquistas del entorno o de los personajes sino en la medida de lo necesario para configurar un ambiente de época mínimo.

Por una parte, el texto evidencia una concepción crítica de la historia por cuanto el desenlace explicita un rechazo por parte del narrador hacia el desorden social y la disgregación de los valores imperantes que en mayor o menor medida se producirían en el devenir de la historia nacional algunos años después del tiempo del relato. Así por ejemplo, doña Elvira retorna a la casa que había arrendado una vez que desaparece la familia disruptora del orden. El caos personal y familiar, preámbulo inevitable del social, ya sea como realidad, amenaza, fantasmagoría o lección de vida, está alegorizado en los personajes individuales de la familia Sandoval-Glicker, en Alex y en el tío César respectivamente, pero no logra imponerse frente al orden representado por la madre, la abuela (en sus dos versiones: una grata y amable y una agresiva y asertiva), especialmente por "el peso de la noche" social y moral: la tradición, la estabilidad, la familia constituida comme il faut, sinécdoque esta de aquel tipo de Estado respaldado en instituciones sólidas que Oswald Spengler denominó "en forma".

Por otra, la implicación ideológica de la historia narrada — en términos de White (32-8) - corresponde evidentemente a una posición conservadora, pues el orden establecido - la casa, el barrio, la familia - no requiere cambios más allá de aquellos que dicta el orden natural. Dice White al respecto: "...los conservadores tienden a ver el cambio social a través de la analogía de gradaciones de tipo vegetal" (34) pues para ellos "...la estructura fundamental de la sociedad es considerada como sólida, y hay algún cambio que aparece como inevitable, pero se considera que el cambio mismo es más eficaz cuando cambian partes particulares de la totalidad, antes que relaciones estructurales" (Ibid.). En este sentido, es interesante anotar que se produce una curiosa anacronía respecto de la implicación ideológica subyacente a la novela, pues dicha implicación corresponde no al tiempo de la escritura sino al de la aventura, ya que es el estado de la sociedad chilena de los años 50 el que aparece reflejado en la diégesis, pero dicha visión no aparece contaminada por el momento de producción del texto. Contextualmente hablando, y a menos que sea posible establecer una disociación radical entre el ámbito cultural y el económico, habría resultado bastante inverosímil postular una implicación conservadora como la planteada en el texto para un momento de la historia nacional como el que se vivía a finales de los años 70, pleno de cambios radicales en una estructura económica capitalista como la chilena, que había permanecido inalterada durante más de cien años, hasta la introducción de políticas desarrollistas generadas e impulsadas por la CEPAL a partir, justamente, de finales de los años 40 e inicios de los 50. Respecto de 
esos cambios, piénsese tan sólo en aquel neoliberalismo extremo que ni siquiera era practicado en el país de origen de sus propugnadores, Milton Friedman y Arnold Harberger, que fue patrocinado en Chile por los llamados Chicago Boys, y que se impuso a la visión nacionalista-proteccionista defendida por otros grupos al interior del Gobierno de esa época. A consecuencia de la implicación ya señalada, en la novela de Rosasco el sistema de valores ideológicos sólidamente asentado en la comunidad no necesita entrar en acción sino opera en su propio mérito, es decir, no precisa de la reacción activa de alguno de sus integrantes, puesto que basta el impulso de auto-conservación de uno de ellos - Alex - para hacer abortar el proyecto de introducción de conductas y valores extraños, disgregadores o inmorales. Por ello, es posible establecer una relación de homología entre la realidad exterior y el texto y constatar la existencia del ideologema, es decir, de la intersección de la sociedad y la historia en cuanto textos en el relato, dado que los personajes adultos actúan como un Super yo que refuerza la ideología imperante en el momento histórico de la escritura, vale decir, en los primeros tiempos de la dictadura que se había propuesto restaurar los valores familiares y patrios distorsionados, cuando no extraviados, durante los 1000 días de Allende.

\section{ALEGORÍAS DE LA VICTORIA}

La Historia la escriben los vencedores; la literatura, los vencidos

Utilizamos parcialmente el título del conocido estudio crítico de Idelber Avelar acerca de la ficción postdictatorial (2000) como contrapunto para examinar la novela de José Luis Rosasco desde la alegoría. Según nuestra hipótesis de trabajo, el discurso que vertebra la diégesis en la novela de Rosasco es el del poder, oculto en una aparente historia de amor romántico adolescente frustrado. En otras palabras, se trata del discurso alegórico del Super yo enmascarado. Desde nuestra perspectiva, Dónde estás Constanza es un relato de legitimación del orden social y familiar, y el procedimiento básico utilizado para lograr el objetivo subyacente remite a una de las categorías de la alegoría (literal, tipológica, tropológica, anagógica) empleadas en la Edad Media: la alegoría moral (o tropológica), que señala cómo uno debe actuar en el presente, y la cual converge en la "moraleja de la historia". En su ensayo "De las alegorías a las novelas" (1980) Borges expone las vicisitudes de la alegoría en el transcurso de la historia intelectual de Occidente e inicia su texto considerándola un error estético, una forma injustificable. Para argumentar, entre otros, acude a Croce, quien señala que la alegoría no sería un modo directo de manifestación espiritual, sino una suerte de escritura o de criptografía. Adicionalmente, Borges sostiene que “...la literatura alegórica [...] es fábula de abstracciones, como la novela lo es de individuos. Las abstracciones están personificadas; por eso, en toda alegoría hay algo novelístico" (270), y llega a la siguiente conclusión: "Los individuos que los novelistas proponen aspiran a genéricos (Dupin es la Razón, Don Segundo Sombra es el Gaucho); en las novelas 
hay un elemento alegórico" (ibid.). Esta idea de Borges tiene bastante sustento en la novela que examinamos, como intentaremos establecer más adelante al momento de señalar las eventuales correspondencias de los términos involucrados en la serie metafórica que vertebra el texto. Para Avelar, por el contrario, "[L]a alegoría sería [...] la expresión estética misma de la desesperanza" (2000:98), y respecto del contexto de plasmación de la alegoría, sostiene que florecería en tiempos de reacción política - Contrarreforma- Segundo Imperio francés, Posmodernidad: "[L]a alegoría es la faz estética de la derrota política [...] no gracias a algún agente extrínseco, controlador, sino porque las imágenes petrificadas de las ruinas [...] conllevan la única posibilidad de narrar la derrota. Las ruinas serían la única materia prima que la alegoría tiene a su disposición" (99). A nuestro juicio, aún cuando Avelar acierta respecto del florecimiento de la alegoría en tiempos de reacción política - tal sería el caso de finales de los años 70 en Chile- a la luz de la serie metafórica que evidencia la novela de Rosasco es oportuno preguntarse si el crítico tiene razón cuando sostiene que sólo hay alegorías de pérdidas; que el duelo por la pérdida es lo que funda el imperativo alegórico, y que el objeto de la alegoría sólo se ofrecería al conocimiento como objeto perdido, en retirada (2000:247). La pregunta es legítima dado que en la realidad extratextual se cumplió casi al pie de la letra el vaticinio formulado de manera soterrada o manifiesta por las fuerzas en pugna en el período previo a septiembre de 1973 en torno a la lucha de clases y a la inevitabilidad del enfrentamiento: efectivamente hubo enfrentamiento - muy limitado dado el desequilibrio en el poder de fuego, en la "competencia" de los respectivos contingentes y en el know how bélico - y triunfó el bando conservador del cual la novela ideológicamente forma parte. Entonces, la alegoría en la novela de Rosasco sería una de la victoria de la sociedad conservadora, no del fracaso o de la ruina benjaminiana, como sí se ha dado en el discurso del bando derrotado. Doris Sommer se refiere a la alegoría como un tipo de narración que contempla la existencia de niveles paralelos de significación temporalmente diferenciados, de manera tal que uno de ellos repite o revela el nivel de significado anterior "...tratando desesperadamente de convertirse en el otro o mirando, desde una distancia meta-narrativa, la futilidad de cualquier intento de acceder a un significado estable" (2004:60).

\section{ALEGORÍAS FUNDACIONALES}

Sommer estudia las novelas nacionales de América Latina como ficciones fundacionales (2004) y, si tomamos este concepto como referencia, la novela de Rosasco se presenta al lector — en clave de novelita rosa juvenil- como una versión restauradora del género, como un pastiche sin autoconciencia tras la tendencia hacia la abstracción alegórica de la novela del Boom. Al referirse a este momento de la novela hispanoamericana, Sommer afirma que "[L]as grandes novelas del Boom re-escriben, o des-escriben, las ficciones fundacionales como el fracaso del romance, la política erótica mal encauzada que no logró jamás unir a 
los padres con las madres nacionales, mucho menos a la gente decente con unas nacientes clase media y popular" (45). A nuestro entender, es en este ámbito donde se inscribe la novela de Rosasco, aunque sólo parcialmente, pues incorpora un aspecto - lo fundacional - de la novela del siglo XIX, pero contaminado por la experiencia posterior y bien específica de la amenaza real o imaginada que se cernió sobre el Estado "en forma" entre 1965 — fecha a partir de la cual se aceleran procesos de cambios que derivarían en una polarización de los actores políticos, como la Reforma Agraria - y 1973. Estas dos versiones del fracaso, la unión de clases sociales y de padres con madres encuentra un sustento claro en la novela que examinamos. Así, la llegada al barrio de la familia (Sandoval)-Glicker desde un pasado y una geografía ignotos, alegoriza la ocupación legal del espacio nacional y la tentativa de rápido (y frustrado) ascenso socioeconómico de las capas medias y populares y su eventual inclusión en el mundo burgués tradicional. En lo referente a la unión de padres y madres, en la novela llama la atención la ausencia de padres fuertes o con existencia real: el señor Sandoval (chileno) es un pícaro gino-dependiente que exhibe una moral laxa, por lo cual la familia descansa en la ambivalente figura de la Madre (alemana) protectora y permisiva a la vez; en tanto que el padre de los Corsiglia está muerto, pero aun así el mundo familiar está en orden. Tal parece que el Gran Padre rector de los destinos nacionales en la época de la escritura hace innecesaria una figura paterna fuerte inter portas. Según Sommer, la novela fundacional es “...aquel libro cuya lectura es exigida en las escuelas secundarias oficiales como fuente de la historia local y orgullo literario" (20). No obstante, en lo que concierne a Dónde estás Constanza - dado su carácter ficcional - es complejo hablar de un texto-fuente para el estudio del pasado, pues se trata de un tipo de literatura edificante que - al modo de Cervantes en el Quijote - opera simultáneamente como “...ejemplo y aviso de lo presente, [y] advertencia de lo por venir..." (1981:52). Por ello, la novela de Rosasco sería una ficción refundacional enderezada a presentar un proyecto de Nación válido para el presente y el futuro, un texto que recobra un orden social y familiar que se trastornaría en un futuro extradiegético post 70 respecto del tiempo de la ficción en los años 50. La recuperación en el universo textual de una época percibida como de una sociabilidad modelo y un orden familiar y comunitario ideales parece ser, en primera instancia, el programa de la obra, como asimismo el poner de relieve que, tras un hiato de algunos años de deterioro y amenaza (en la actualidad post 1970-73) se han logrado crear las condiciones para retomar la senda extraviada. Y es en este contexto donde cobra entonces validez lo que sostiene Walter Benjamin respecto de la alegoría cuando expresa que “...uno de los móviles más poderosos de la alegoría es la intuición de la caducidad de las cosas y el cuidado por salvarlas en lo eterno" (20062008:220). Además, en el ámbito de los tiempos involucrados en la diégesis se produce un interesante juego temporal, pues la amenaza de descomposición que se 
cierne sobre el universo intratextual opera prolépticamente al anticipar la amenaza real, potencial o imaginada que desde la perspectiva conservadora se produjo en el universo extratextual correspondiente al sector social - alegorizado por los Corsiglia - entre los años 1970-1973. Por ello, y dado que como afirma Sommer en la alegoría la nostalgia es inevitable (65), el lector - tomando en cuenta el año de publicación del texto- puede realizar la triple operación de coordinar los tiempos involucrados en su tiempo de lectura, digamos 2010, desde el cual puede evaluar con conocimiento de causa aquella homología entre la realidad exterior y la realidad del texto que Julia Kristeva denomina el ideologema, según el cual la narración constituye una estructura, la economía otra, la política otra, y la intersección de estas estructuras en el texto forma el mencionado ideologema (1981:15-6). Triple operación, pues la novela de Rosasco de 1980 sitúa la diégesis en los años 50 y construye un texto alegórico que, si bien desde los 80 mira hacia el pasado, al mismo tiempo remite hacia el futuro de fines de los años 60 y comienzos de los 70 hasta nuestro 11 de septiembre de 1973. Por lo tanto, en el caso de Dónde estás Constanza se trata de una singular especie de alegoría proyectiva -0 anagógica en la terminología medieval - pues anuncia desde el mundo del relato lo que sucederá pocos años después, con un componente nostálgico que recupera una época en la que Nación y Estado estaban "en forma".

Por otra parte, es interesante detenerse un momento en la categoría "romance" inscrita en el texto. Para Sommer, el romance es "...la intersección entre nuestro uso contemporáneo del vocablo como historia de amor y el uso del siglo XIX que distinguía al género como más alegórico que la novela" (2004:22). No obstante, el romance nacional del siglo XIX analizado por Sommer en novelas como Amalia, María o Martín Rivas, se ha transformado en 1980 en una suerte de negación debido a que los héroes involucrados, especialmente la protagonista femenina, no intentan construir un romance en el marco de las reglas a estas alturas ya consolidadas, sino una utopía que Hayden White denominaría anárquica, dada su proyección hacia una edad de oro sin viabilidad en la época de la escritura de la novela, tras las experiencias de las distintas clases de utopías conjuradas, reprimidas, fracasadas o falsificadas en las dos décadas anteriores. En el caso de Chile, cuando hablamos de "utopía" nos referimos a lo que se dio en llamar el experimento allendista ("con empanadas y vino tinto") que para el sector conservador resultaron intragables por la introducción de ingredientes foráneos en la receta; y con un tinto que no alcanzó a tener suficiente cuerpo por falta de maduración.

Para los efectos de considerar en nuestro análisis a la novela de Rosasco como una alegoría social-nacional, Cánovas, siguiendo el texto de Sommer, nos recuerda que las uniones amorosas tienen carácter alegórico en el ámbito de fundación de la nación (2003:15) y, en este sentido, vale la pena destacar el contexto de producción de la novela — la segunda mitad de la década de los 70 cuando el proyecto matriz que se dio la Junta Militar chilena en 1973 destacaba 
nítidamente un carácter re-fundacional como su principal razón de ser y de actuar. Este carácter se pudo incluso apreciar en el detalle de fijar en la nueva sede de Gobierno, rebautizada de Gabriela Mistral a Diego Portales, una placa con las fechas inaugurales 1810-1973. La siguiente cita del texto de Doris Sommer hace innecesaria una explicación demasiado morosa acerca de la relación entre el contexto de producción de la historia de Rosasco y el devenir histórico del género de la novela fundacional en América Latina

...los regímenes latinoamericanos se decidieron [en las primeras décadas del siglo XX] por programas patrióticos para fomentar el desarrollo económico y cívico como respuestas a la Depresión y a la competencia representada por las ideologías "extranjeras". En otras palabras, dichos Estados aceptaron tácitamente las fabricaciones literarias del siglo XIX como las ficciones fundadoras donde se forjó el deseo de un gobierno autoritario a partir de la materia aparentemente prima del amor erótico (2004:69).

No obstante, el incipiente romance de Dónde estás Constanza parece a primera vista una especie de crónica de un fracaso anunciado - utilizando la expresión ya casi deslegitimada por el abuso- pues la ostensible precariedad de sus fundamentos materiales y sicológicos garantiza el rápido deterioro y la resolución dolorosa, pero necesaria. De otro modo, de persistir y triunfar el pensamiento utópico que sirve de plataforma a la aventura de los pre-púberes, se pone en peligro el tejido macrosocial en el espacio armónico del universo diegético. En el proyecto implícito en la novela de Rosasco de maridar la utopía representada por Constanza con el "buen sentido nacional" encarnado en Álex, a todas luces una mésalliance, se diagrama alegóricamente la irrealidad, incluso la insensatez del experimento social emprendido por el gobierno de la Unidad Popular entre 1970 y 1973. El desenlace de la historia patentiza que no hay espacio para desviaciones de la recta norma que ha conducido y servido de fundamento a la historia nacional, y que ha permitido la prevalencia de bienes como la tradición, la familia y la propiedad, tan caros al auténtico espíritu nacional amenazado por ideologías foráneas que se infiltran como un cáncer, y que conviene extirpar radicalmente, como sostuvo alegóricamente un integrante posteriormente defenestrado de la Junta Militar. Por eso, y como otro ejemplo de la inserción de la Historia en el texto, al final del relato la familia disruptora simplemente desaparece. Tras su retorno al hogar, al preguntar Álex por los Sandoval-Glicker, su hermano Luis le informa: "Vinieron los carabineros, después apareció una carretela, y se fueron [...] se mudaron y se fondearon para siempre [...] nadie sabe nada [...] nadie los ubicará" (109). En lo económico han dejado una estela de deudas [que admite el parangón con la alta tasa de inflación de 1973], y respecto de su vínculo con los adultos de la familia-Nación Corsiglia, en estos prevalece una sensación de alivio, de haberse librado, gracias al influjo que ejerce en Álex el "peso de la noche", de caer en el 
caos, en la disolución. En virtud de esta fuerza actuante, la comunidad conserva la sofrosine, es decir, el autodominio, la disciplina y la moderación que han provocado aquellas mistificaciones como la de considerarnos los ingleses de Sudamérica. En este sentido, la novela de Rosasco constituye una exitosa articulación política de la frustración erótica que experimentan ambos protagonistas, pues si en la novela fundacional del siglo XIX la articulación entre Eros y Polis adquiere un carácter positivo como requisito del género y como imperativo de la hora, en Dónde estás Constanza la negatividad implicada en el fracaso del proyecto erótico igualmente se revertirá en provecho para los objetivos de la Nación que en 1980 está en pleno proceso de refundación desde sus bases políticas, económicas y culturales.

\section{¿DÓNDE ESTÁ CONSTANZA?}

Y a propósito de personajes desaparecidos, fondeados, extraviados o perdidos, en su título - y como parte consciente o inconsciente del discurso oficialno oficial - la novela de Rosasco alegoriza, malgré lui, la situación y el destino de un número de personas detenidas y desaparecidas cuyo paradero ha sido arduo de detectar. A la fecha, aún no se sabe con certeza qué sucedió con algunas víctimas de la represión ejercida por la dictadura, y en los procesos que se han llevado a cabo los tribunales de justicia han recurrido a la figura jurídica del secuestro permanente para poder sostener los casos de personas cuyo paradero se ignora. En sus desfiles, actos y manifestaciones públicas en general, los parientes de esos desaparecidos han exigido a los sucesivos gobiernos, al Poder Judicial y a los institutos armados conocer el destino de sus familiares para poder completar el duelo y no persistir en la melancolía, dada la evidencia de su muerte; y entre otros recursos comunicativos, han enarbolado pancartas o lienzos inscritos con la pregunta ¿Dónde están?, y con fotos de los desaparecidos. Es la misma pregunta que se hace Álex al final de la novela, pero en él no está presente la desesperanza lacerante ni la certidumbre de lo ominoso, sino más bien, como señala el relato, una anticipada nostalgia. En consecuencia, no subsistirá en él la melancolía de la identificación con el objeto perdido, sino que se producirá la efectiva separación de éste, propia del duelo.

\section{IMAGINARIOS DEL PODER}

Cuando niños recibimos, a través de cuentos maravillosos como Hansel y Gretel, un cierto tipo de educación moral al nivel de la conciencia y del subconsciente. El relato de Hansel y Gretel simboliza el pasaje de una etapa de dependencia hacia una de autonomía e individuación, y así incorporamos —on mayor o menor éxito- a nuestro acervo moral y espiritual valores y actitudes como la solidaridad, la generosidad, la valentía, la superación de los obstáculos, el autocontrol, la autonomía. Como sabemos, todos y cada uno de los elementos de ese cuento refiere a un aspecto del universo extratextual: el bosque, el camino, las migas de pan, las piedrecillas, la bruja, la casa de turrón, las joyas, etc. La novela de Rosasco funciona de manera similar, pues se sitúa entre el cuento de hadas y una 
versión extremadamente simplificada del Bildungsroman, pero a diferencia del cuento de hadas dirigido a la etapa infantil de la vida, este texto se orienta a preadolescentes y adolescentes, un grupo etario al cual es plausible iniciar en los valores, actitudes y normas del futuro ciudadano ejemplar que desea y necesita formar la superestructura para su estabilidad y conservación en el tiempo. Y en este sentido, Dónde estás Constanza adquiere una singular proximidad con la alegoría medieval y con lo que expresaba Borges respecto del carácter genérico de los individuos en las novelas, dado que la mayoría de los personajes son alegorías con disjecta membra y un valor representativo específico en la diégesis. Así, Álex sería la Moderación y el Buen Sentido sometido a prueba; Constanza, la Tentación Vencida; la madre y la abuela de Álex, la Recta Moral triunfadora; el señor Sandoval-Glicker, la Disipación castigada; la señora Glicker, la Tolerancia, la Benevolencia y la Permisibilidad; la Rucia, hermana mayor de Constanza, la Concupiscencia; Jaime, el amigo de Álex, la Fidelidad. Además, un espacio tan importante en la novela como es el barrio de Álex constituye el escenario adecuado para la representación del locus amoenus; mientras la casa de los Sandoval-Glicker representa su opuesto, la precariedad, la inseguridad, lo inconcluso. A lo largo de tres décadas, cientos de miles de preadolescentes chilenos han leído esta novela por mero placer o como parte de las lecturas de los programas de estudio, y los efectos que ella ha tenido en la formación, en la construcción de imaginarios del poder y en las decisiones públicas y privadas de esta generación acaso pudieran ser objeto de una investigación de carácter sociológico, sicológico, literario y/o político que supera los límites de este trabajo.

\author{
Pontificia Universidad Católica de Chile* \\ Facultad de Letras, Departamento de Literatura \\ Avda. Vicuña Mackenna 4860, Macul. Santiago (Chile) \\ mlillo@uc.cl
}

\title{
BIBLIOGRAFÍA
}

Ahumada, Jorge. En vez de la miseria, Santiago de Chile: Los Andes, 2000.

Avelar, Idelber. Alegorías de la derrota. La ficción postdictatorial y el trabajo de duelo. Santiago de Chile: Cuarto Propio, 2000.

Benjamin, Walter. "Origen del Trauerspiel alemán", en Obras. Rolf Tiedemann y Hermann Schweppenhäuser. Madrid: Abada, 2006-2008.

Böll, Heinrich. "Bekenntnis zur Trümmerliteratur", en Das Heinrich Böll Lesebuch. Victor Böll (Ed.). München: Deutscher Taschenbuch Verlag, 1982:96-100.

Borges, Jorge Luis. "De las alegorías a las novelas", en Otras Inquisiciones. Prosa completa. Barcelona: Bruguera, 1980:267-70.

Cánovas, Rodrigo. Sexualidad y cultura en la novela hispanoamericana. La alegoría del prostíbulo. Santiago de Chile: LOM, 2003.

Cervantes, Miguel de. El ingenioso hidalgo Don Quijote de La Mancha. (19² Ed.). Madrid: Espasa Calpe, 1981. 
Correa, Sofía, et al. Historia del siglo XX chileno. Santiago de Chile: Sudamericana, 2001.

Jocelyn-Holt, Alfredo. Espejo retrovisor. Santiago de Chile: Planeta/Ariel, 2000.

Kristeva, Julia. El texto de la novela. (1974). (Trad. Jordi Llovet). Barcelona: Lumen, 1981.

Nietzsche, Friedrich. "Vom Nutzen und Nachteil der Historie für das Leben". Unzeitgemässe Betrachtungen, Zweites Stück en Werke in zwei Bänden. München: Carl Hanser Verlag, 1967:113-74. (Traducción anónima en www.elabedul.net/Documentos/de_la_utilidad.doc). Consultado: julio 5 del 2006.

Pinto, Aníbal. Un caso de desarrollo frustrado. Santiago de Chile: Universitaria, 1962.

Rosasco, José Luis. ¿Dónde estás Constanza? ( $3^{\circ}$ Ed. 1981). Santiago de Chile: Andrés Bello, 1980.

Sommer, Doris. Ficciones fundacionales. Las novelas nacionales de América Latina. Bogotá: F.C.E., 2004.

White, Hayden. Metahistoria. La imaginación histórica en la Europa del siglo XIX. México: F.C.E., 1992. 